\title{
Putting the "E" in SES: unpacking the ecology in the Ostrom social- ecological system framework
}

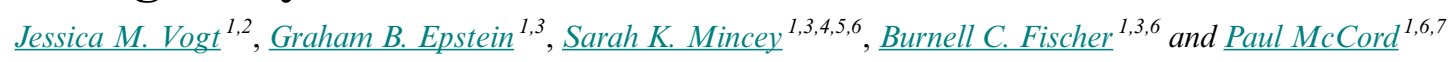

\begin{abstract}
The Ostrom social-ecological system (SES) framework offers an interdisciplinary tool for studies of linked human-natural systems. However, its origin in the social sciences belies the effectiveness of its interdisciplinary ambitions and undermines its ability to cope with ecological complexity. To narrow the gap between inherently dynamic ecological systems and the SES framework, we need to explicitly recognize that SES outcomes are coproduced by social systems in which choices are made, as well as an ecological system with a diverse assortment of dynamic natural processes that mediate the effect of those choices. We illustrate the need for more explicit incorporation of ecological attributes into the SES framework by presenting a case study of a community-managed forest in Indiana, USA. A preliminary set of ecological attributes are also proposed for inclusion in the SES framework with the aim of spurring interest in further development of a truly interdisciplinary framework for the study of SESs.
\end{abstract}

Key Words: ecological theory; forest ecology; interdisciplinary science; linked human-natural systems; social-ecological system framework

\section{INTRODUCTION}

In recent years, trends toward increasing specialization to resolve environmental problems have abated and even reversed, reflecting growing evidence that social and ecological systems are inextricably linked. In recognition of these linkages and the analytical complexity they entail, the late Nobel Laureate Elinor Ostrom introduced the social-ecological system (SES) framework as an interdisciplinary diagnostic tool for the study of complex SESs (Ostrom 2007a). Based on decades of research on common property governance, the SES framework suggests that socialecological outcomes such as sustainability of a resource system are a function of the complex interactions among the diverse social and ecological components of that system (Ostrom 2007a, 2009). The SES framework proposes that characteristics of the Resource System, Resource Units, Actors, and Governance System interact in an action situation to produce observed socialecological outcomes (McGinnis and Ostrom 2014; Fig. 1). However, although the two main introductions to the SES framework (Ostrom 2007a, 2009) have together been cited more than 1700 times, few researchers have actually operationalized the framework for empirical inquiry and even fewer had considered the effects of ecological attributes and processes (Epstein et al. 2013).

We suggest that the general absence of ecological considerations within the SES framework stems from the continuing absence of a meaningful interdisciplinary dialogue and vocabulary. Epstein et al. (2013) proposed the addition of Ecological Rules as a toptier subsystem equally as important as social, economic, and political systems and related ecosystems for the interactions between resources, actors, and governance as represented in the SES framework (Fig. 1). We built on the work of Epstein et al. (2013) to show how dynamic ecological processes can be meaningfully incorporated in studies of SESs. We use a twopronged approach: First, we describe an illustrative case
Fig. 1. The social-ecological system framework consists of four core subsystems (RS, RU, GS, A) organized around a central action situation in which interactions occur and outcomes are produced. Additional subsystems (S, ECO, ER) impact all core subsystems. Figure is based on Ostrom (2009) and Epstein et al. (2013).

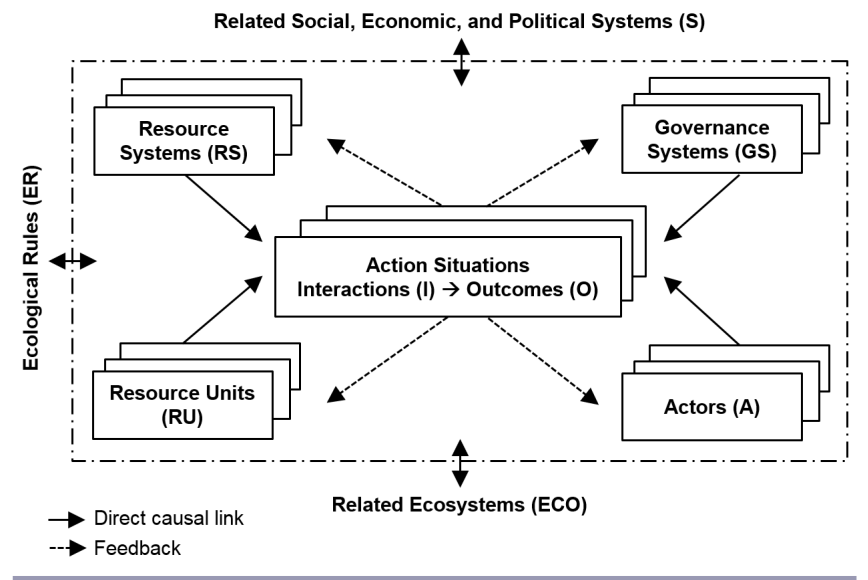

study of forest management in south-central Indiana where, despite the stability of social processes and governing institutions, dynamic ecological processes related to forest succession are transforming the species composition of the forest toward a less diverse and arguably less ecologically valuable state. This case study is an example of the type of SES in which a lack of explicit incorporation of ecological principles yields an incomplete understanding of observed outcomes. Second, we propose addition of some previously omitted variables to the SES framework to enhance its capacity for diagnosis and rule-based

\footnotetext{
${ }^{1}$ The Vincent and Elinor Ostrom Workshop in Political Theory and Policy Analysis, Indiana University Bloomington, ${ }^{2}$ Department of Earth and Environmental Sciences, Furman University, ${ }^{3}$ School of Public and Environmental Affairs (SPEA), Indiana University Bloomington, ${ }^{4}$ Integrated Program in the Environment, Indiana University Bloomington, ${ }^{5}$ Indiana University Research and Teaching Preserve, ${ }^{6}$ Center for the Study of Institutions, Population and Environmental Change (CIPEC), Indiana University Bloomington, ${ }^{7}$ Department of Geography, Indiana University Bloomington
} 
ecological reasoning. The suggested variables are meant to stimulate discussion among SES researchers about the formal inclusion of ecological theories and variables in the SES framework.

The general absence of ecology in the SES framework and associated lack of interest from natural scientists are unfortunate given that both social and ecological processes matter to SES outcomes. Ecologists can argue that they have other frameworks and modeling tools that are more useful for understanding the ecology of a system or ecological processes. Although many scholars of ecology and geology proclaim a new era characterized by human influence on land, air, sea, and even global climate (the "Anthropocene"; e.g., Steffen et al. 2011, Gowdy and Krall 2013), many models invariably overlook the underlying drivers and potential policy responses to environmental problems. Social scientists create similar dilemmas as they call for more integration and interdisciplinary research while often failing to take heed of basic ecology (Holling 2000, Redman et al. 2004). Ostrom herself (2009) adds to this problem by placing the action situation, a general game theoretic model of institutionally mediated choice, at the center of her interdisciplinary framework. This implies that all outcomes in SESs can be understood in terms of social processes and in aggregations of human decisions, and that ecological processes matter only insofar as they present a collective-action problem related to the collection and processing of information. However, ecological processes do matter and can yield substantively different results despite similarities in the outcomes of social processes. For instance Genkai-Cato and Carpenter (2005) demonstrate how the effects of anthropogenic, i.e., socially driven, phosphorus inputs on the trophic state of a lake depend on its size, depth, and temperature, and the presence of aquatic macrophytes because all these influence dynamic biological production and phosphorus recycling processes. In light of the fact that both ecology and society matter for the sustainability of SESs, we need a systematic approach to evaluate the effects of ecological and social processes and their interactions.

We built on nearly a decade of published, i.e., peer reviewed and white paper, and unpublished, i.e., working group, research and development on the SES framework. We argue that the SES framework remains a promising tool that could benefit from more explicit incorporation of ecological theory, models, and concepts. A case study of forest dynamics in south-central Indiana clearly illustrates how social and ecological processes have jointly led to an ongoing shift in the species composition of a forest. This shift is driven by dynamic forest succession processes in light of collective choices that favor fire suppression and passive conservation, i.e., conservation that precludes active management of the forest landscape by managers. We seek to narrow the gap between the language of the SES framework and that used by ecologists by proposing a preliminary list of third-tier ecological variables for the framework to demonstrate how important ecological concepts can be integrated. Greater synthesis is possible across the social and natural science divide with a revised framework.

\section{FOREST DYNAMICS IN YELLOWWOOD LAKE WATERSHED}

The SES framework emerged from decades of research on common-pool resources, with important contributions from the study of forest ecosystems (e.g., Gibson et al. 2005, Chhatre and Agrawal 2009). The International Forestry Resources and Institutions (IFRI) research program has proved particularly influential because it seeks to understand how social, institutional, and biophysical factors interact to impact forest outcomes (http://sitemaker.umich.edu/ifri/home). Recent IFRI research has found that local participation, autonomy, and ownership of forest resources increase the likelihood of more sustainable patterns of use, i.e., use that enables a persistent, longlasting resource management system (e.g., Chhatre and Agrawal 2009, Persha et al. 2011). This observation adds to prior research that found that the likelihood of sustainability covaries with local monitoring and sanctioning (e.g., Gibson et al. 2005, Chhatre and Agrawal 2008, Coleman 2009) and secure tenure (e.g., Pagdee et al. 2006). Although these factors may inform forest management and policy, it remains unclear whether they are independent of the underlying ecological context, or whether the effects of institutions depend on interactions between choice and ecology in such a way as to support sustainable exploitation of forest resources. Although the former seems unlikely, much of the common-pool resource and SES literature implicitly presumes that ecology plays a limited role in observed forest commons outcomes. A case study of Yellowwood Lake Watershed (YLW), an IFRI training site in south-central Indiana, illustrates the potentially problematic nature of this presumption by revealing clear interactions between human decision making and ecology as it relates to the changing species composition of the forest.

\section{Background}

YLW is situated in the temperate northern hardwood forests region. It is characterized by unglaciated karst topography with relatively narrow hills and ravines among frequent steep slopes (Homoya et al. 1985). YLW comprises approximately 4410 acres (1785 ha), most of which (3500 acres [1416 ha]) is publicly owned and managed by the Indiana Department of Natural Resources Division of Forestry as part of Yellowwood State Forest. Yellowwood Lake, a small reservoir, is located at the southern end of the watershed. The remainder of YLW consists of 55 privately owned parcels in the central and northern region of the area (YLWPG 2006).

Results from a 2008 visit by IFRI researchers detail the ecological condition of the forest (Arnold et al. 2008). White oak (Quercus alba) and sugar maple (Acer saccharum) dominate among the larger trees in the forest canopy (diameter at breast height [dbh] greater than $10 \mathrm{~cm}$ ), along with American beech (Fagus grandifolia), chestnut oak (Quercus prinus), and tulip poplar (Liriodendron tulipifera). Dominance is indicated by the importance value for each species based on Husch et al. (2003). However, oaks are absent from the list of most dominant saplings in the understory ( $\mathrm{dbh} 2.5-10 \mathrm{~cm}$ ), which include American beech, red maple (Acer rubrum), sugar maple, sassafras (Sassafras albidum), and tulip poplar. Pure species abundance is similar to importance values, with sugar maple having more than three times the tree stem density of the next densest tree species and American beech having more than twice the sapling density of any other sapling species. This suggests that YLW forests are currently undergoing the dynamic process of forest succession wherein the relative dominance of oaks in the forest is declining over time as mature white and chestnut oak trees are replaced by a mixture of maple and beech trees (Arnold et al. 2008). 
Long-standing disagreements regarding the best use and management practices for YLW forests have resulted in the creation of the YLW Planning Group, which comprises local stakeholder groups, individual landowners, and the local Department of Natural Resources forest manager. Although most of the area is used for recreation, stakeholder disagreements center on potential timbering of small forest tracts. Historically, Indiana forests were dominated by early-successional species such as oak (Quercus) and hickory (Carya), but the forests are currently transitioning to later-successional beech (Fagus) and maple (Acer; Homoya et al. 1985, Pierce et al. 2006, Arnold et al. 2008). Department of Natural Resources forest managers are concerned about the decline of oak and hickory trees in YLW that are valuable to the hardwood industry and as mast producers for wildlife. Therefore, to meet desired future forest conditions for the watershed, they periodically prescribe forest management activities that include timber harvesting to create light openings in the forest, which favors the growth of sun-loving oak and hickory trees (YLWPG 2006, Arnold et al. 2008, IDNR 2008). However, local landowners and other interest groups simply prefer old-growth forests regardless of the species composition of that forest, and oppose any and all logging activities (YLWPG 2006, Arnold et al. 2008). These tensions have ultimately resulted in a forest management strategy that is characterized by political stalemate and inaction, which nonetheless reflects the antilogging preferences of the majority.

\section{Applying the SES framework to YLW}

The SES framework as modified by Epstein et al. (2013) aids analysis of outcomes in complex SESs such as YLW by conceptualizing much of the rich detail of a case in terms of a common set of components, attributes, and processes. In general, one or more components of a SES such as an actor or actor groups, a resource, or set of resources interact with one another in one or more social, ecological, or social-ecological processes, whose outcome depends on the attributes of those components and the processes that govern their interactions. The species composition of YLW forest can largely be understood with reference to one social and one ecological process.

The social process at play in YLW can be understood as an action situation consisting of three actors with different rights, responsibilities, and preferences regarding forest management decisions. YLW is managed by a forest manager who must consult with stakeholders regarding decisions on forest use; the forest manager then reports decisions to and gets approval from the state forester. In the action situation, the forest manager is faced with a choice to harvest portions of YLW or conserve. Given that YLW is part of a Yellowwood State Forest, a complete harvest or clearcutting of the forest is not a feasible alternative at this time. Thus, the two main options are limited harvest or complete protection. Stakeholders can be defined by their preferences: (1) foresters and logging interests that would prefer to harvest portions of the forest and (2) recreational users and local landowners who would prefer to conserve the forest in its "natural state." If we assume that the forest manager finds it useful to maximize the number of happy stakeholders through symmetric aggregation, i.e., one person, one vote, the choice to harvest or conserve can be modeled as a function of the relative distribution of expressed preferences. Given that the number of recreational users and landowners vastly exceeds the number of harvesters, e.g., more than 5000 campers annually plus countless day users compared with only a few individuals and organizations involved in timber harvesting (Arnold et al. 2008), we can predict that the collective-choice process would tend to favor conservation, as was observed by Arnold et al. (2008). In the language of the SES framework (Table 1), the choice to conserve all forest resources, i.e., to not harvest (I1), can be understood in terms of the number of relevant actors in each stakeholder group (A1), their respective preferences drawn from economic (RU4) and normative (A6) factors, and the symmetric collective-choice aggregation rule. These components and attributes can be used to provide a sufficient account regarding current species compositions in YLW forest, given the absence of major disturbance events in its recent history. They do not, however, provide a sufficient account or explanation as to why the species composition of the forest is changing from oakhickory to beech-maple despite the stability of social processes.

The ecological process at play in YLW forest can be understood by examining the dynamic processes of forest succession. YLW forest, as mentioned previously, is currently transitioning from an oak-hickory forest to a beech-maple forest as a result of ecological mechanisms that affect the germination, growth, and survival of tree species. First, YLW is located in the central hardwood region, which imposes biogeographic constraints that limit the species pool to those that are able to survive in temperate climates. Second, competition between species with different competitive abilities drives the forest succession processes taking place at YLW in the absence of active management by humans. Oaks are a moderately shade-intolerant group of species with comparatively high minimum light requirements (Abrams 2003). As the oaks and other early-successional species grew and gradually formed a forest canopy, light availability at the forest floor decreased, favoring the growth of the shade-tolerant beeches and maples that are beginning to dominate YLW forest. Finally, a full picture of the ecology of YLW is incomplete without considering the important influence of fire dynamics in temperate North America. Native Americans historically managed fires in much of the forested central and eastern North American continent, resulting in species compositions dominated by fire-tolerant, disturbance-adapted, shade-intolerant white oak species (Pierce et al. 2006). During the colonial period and into the present day, fire suppression became the dominant management paradigm and regeneration of oaks in the understory became less common in relatively undisturbed, unlogged forests, starting the ongoing and larger scale transition to non-disturbance-adapted maple and beech forests (Abrams 2003).

The language of the SES framework as adapted by Epstein et al. (2013) can be used to characterize the forest transition in terms of a fairly small set of influential attributes and processes. First, the geographical location of the forest (RS9; see Table 1) is an important contextual attribute that determines the set of species that can successfully germinate, grow, and reproduce in the forest given the underlying temperature, precipitation, and soil nutrient profile of the region. Next, two important attributes, light availability at the forest floor, which can generally be characterized in terms of system productivity (RS5), and dynamic competitive interactions (RU3) between shade-tolerant beech and maple and shade-intolerant oak and hickory have led to the ongoing forest transition. Whereas forest succession is well studied by ecologists, the SES framework presented by Ostrom $(2007 a, 2009)$ is unable to account for this dynamic ecological process; in characterizing the ecology of the forest system, we have had to apply additional 
Table 1. Attributes of subsystems of the social-ecological system (SES) framework. Table is from Epstein et al. (2013) and is used under a Creative Commons Attribution 3.0 License.

Social, Economic, and Political Settings (S)

S1- Economic development. S2- Demographic trends. S3- Political stability.

S4- Other governance systems. S5- Markets. S6- Media organizations. S7- Technology.

Resource Systems (RS)

RS1- Sector (e.g., water, forests, pasture)

RS2- Clarity of system boundaries

RS3- Size of resource system

RS4- Human-constructed facilities

RS5- Productivity of system

RS6- Equilibrium properties

RS7- Predictability of system dynamics

RS8- Storage characteristics

RS9- Location

Ecological Rules

(ER)

ER1- Physical

rules.

ER2- Chemical

rules.

ER3- Biological

rules.
Resource Units (RU)

RU1- Resource unit mobility

RU2- Growth or replacement rate

RU3- Interaction among resource units

RU4- Economic value

RU5- Number of units

RU6- Distinctive characteristics

RU7- Spatial and temporal distribution
Governance Systems (GS)

GS1- Government organizations

GS2- Nongovernment organizations

GS3- Network structure

GS4- Property-rights systems

GS5- Operational-choice rules

GS6- Collective-choice rules

GS7- Constitutional-choice rules

GS8- Monitoring and sanctioning rules

Actors (A)

A1- Number of relevant actors

A2- Socioeconomic attributes

A3- History or past experiences

A4- Location

A5- Leadership/entrepreneurship

A6- Norms (trust-reciprocity)/ social capital

A7- Knowledge of SES/mental models

A8- Importance of resource (dependence)

A9- Technologies available

Activities and Processes:

I1- Harvesting

I2- Information sharing

I3- Deliberation processes

I4- Conflicts

I5- Investment activities

I6- Lobbying activities

I7- Self-organizing activities

I8- Networking activities

I9- Monitoring activities

I10- Evaluative activities
Action Situations: Interactions (I) $\rightarrow$ Outcomes $(\mathrm{O})$

Outcome Criteria:

O1- Social performance measures

(e.g., efficiency, equity, accountability, sustainability)

O2- Ecological performance measures

(e.g., overharvested, resilience, biodiversity, sustainability)

O3- Externalities to other SESs

Related Ecosystems (ECO)

ECO1- Climate patterns. ECO2- Pollution patterns. ECO3- Flows into and out of focal SES

ecological knowledge to extrapolate forest succession processes from the original variables RS5 (productivity) and RU3 (competitive interactions). We might invoke ecological interpretations of variable RS7 (predictability of system dynamics) to aid in explanation of system outcomes.

The application of the SES framework to YLW is improved by the addition of ecological rules in Epstein et al. (2013) and explicit recognition that dynamic ecological processes are at least as relevant as the social processes commonly associated with commons theory. In the case of YLW forest, the ongoing change in species composition is driven by rules related to natural selection (ER3), a biological process that favors species that are better equipped to survive (RU3) in the presence of a limiting resource (RS5), in this case light availability. Therefore, the dynamic ecological selection process at the present time can and should be seen as the proximal driver of ongoing forest succession that has nonetheless been enabled by the choice to prohibit all harvesting within YLW forest.

We have shown so far that the absence of ecology in the SES framework (Ostrom 2007a, 2009) may lead to an incomplete and inadequate diagnosis of the processes and attributes that affect social-ecological outcomes. By adopting the changes presented in Epstein et al. (2013), we are better equipped to describe and explain outcomes in SESs. However, the above application is still perhaps too far removed from the analytical approach and terminology of the natural sciences, most notably ecology. The variables we used from the SES framework (RU3, RS4, RS9) are not explicitly connected to the ecological principles that we have indicated drive forest dynamics; a nonecologist may not be able to interpret YLW dynamics using the SES framework. However, the SES framework can be further enhanced to capture ecological concepts and processes, and spur interest in interdisciplinary dialogue and development.

\section{UNPACKING THE ECOLOGY}

The SES framework is built on the presumption that knowledge advances swiftly when scholars are equipped with tools that allow for systematic comparisons across multiple methods (Poteete et al. 2010) and across multiple systems (Ostrom and Cox 2010). The game theoretic model at the core of the SES framework (Ostrom 2005) can be operationalized with the specification of 
key variables to advance social research in SESs. However, in most applications of the SES framework, ecological models are noteworthy only in their absence. This omission is unfortunate and, as the case of YLW forest exemplifies, leaves a considerable gap between the decisions that people make, i.e., the social processes, and the observed ecological SES outcomes. Without a more complete specification of ecological variables relevant to the functioning of an SES and the identification of dynamic ecological processes, diagnosis of cases and accumulation of knowledge across methods are stifled.

Clear specification of ecological processes opens the door to a wide range of deductive modes of inquiry. For example, rulebased reasoning may allow scholars to identify ecological attributes that facilitate or limit the effectiveness of alternative environmental policies in individual cases (Cox 2011). For instance, scientific knowledge concerning interactions between ozone and a wide range of ozone-depleting substances allowed for the development of policies to rapidly phase out the most damaging substances, while allowing for a more gradual elimination of less-damaging substances (Benedick 1998, Parson 2003). Moreover, rule-based reasoning provides a systematic way to link insights and knowledge from formal and agent-based models to experiments and other empirical research, thereby facilitating the accumulation of knowledge. In fact, recent advances in experimental methods have begun to draw attention to the role that variations in ecological dynamics play in the choice of operational rules (Janssen 2010). We propose addition of some previously omitted variables to the SES framework to enhance its capacity for diagnosis and rule-based ecological reasoning.

\section{Omitted variables}

Although we can explain a version of the observed outcomes at YLW using the existing SES framework attributes, we cannot fully understand the ecological dynamics influencing outcomes using the existing framework. A better explanation can be generated by adding relevant ecological attributes that affect ecological processes. Most notable in the context of YLW are the effects of local ecosystem history that set the stage or initial conditions for the processes and outcomes we observe in the present day. The addition of an attribute in the Resource System core subsystem, RS10 (ecosystem history), could be used to enhance the flexibility and diagnostic capacity of the framework and provide an ecological analogue for the actor variables that can now specifically account for the social dimension of historical patterns of use (A3; Table 1). Understanding the relevant geologic and disturbance regimes of a resource system may also be used to link outcomes or portions thereof to historical causes. For instance, historical fire dynamics explain why the YLW forest only recently began transitioning from an oak-hickory to a beech-maple forest, its expected climax state.

To further advance the framework for interdisciplinary and multimethod diagnostic inquiry, we unpacked the Resource System (RS) and Resource Unit (RU) core subsystems and demonstrated how ecological concepts can be integrated within these subsystems (Table 2). The third-tier variables listed in Table 2 were determined through deliberations among the authors, informal consultation with ecological experts, and scattered surveys of topic indices in ecological textbooks and course syllabi. Our intent was not to derive an exhaustive list of potentially relevant ecological variables, but rather to provide a list that could serve as a starting point for discussions among SES researchers about the inclusion of specific ecological variables in the framework. Although space limitations preclude explanation of every third-tier variable in Table 2, Box 1 provides justification for our inclusion of four third-tier variables using current ecological theory as examples of how ecological theory might inform thirdtier variable selection. Overall, explicit incorporation of ecological attributes into the SES framework will make the framework easier for social and natural scientists to operationalize, i.e., define and measure, for research.

Table 2. Proposed ecological attributes (numbered RS2-a, RS2-b, etc.) in the Resource System (RS) and Resource Unit (RU) core subsystems, to explicitly incorporate ecological principles into the social-ecological system (SES) framework.

Resource systems (RS)

RS1 Sector (e.g., water, forests, pasture, fish)

RS2 Clarity of system boundaries

RS2-a Ecologically defined boundaries of the resource system (e.g., watershed, ecological zone boundaries, etc.)

RS2-b User-defined boundaries of a resource system

RS2-c Contiguity of resource system to adjacent ecosystems of the same type (e.g., type and quality of matrix ecosystems)

RS3 Size of resource system

RS3-a Extent of resource system in geographic area

RS3-b Resource system shape or configuration (e.g., edge to interior ratio)

RS3-c Fragmentation dynamics

RS3-d Size of different habitat or ecosystem types within the resource system (mosaic features)

RS4 Human-constructed facilities

RS4-a Facilitation of ecological movement (e.g., sewage outflows, species corridors)

RS4-b Impediments to ecological movement (e.g., dams, fences, roads)

RS5 Productivity of system

RS5-a Resource dynamics (e.g., water, light, nutrient availability)

RS5-b Community/species composition

RS6 Equilibrium properties

RS6-a Successional stage/trajectory

RS6-b Existence of alternative stable states and thresholds between states

RS6-c Frequency/timing of disturbance(s)

RS6-d Extent of disturbance(s)

RS6-e Magnitude/intensity of disturbance(s)

RS7 Predictability of system dynamic

RS7-a Stochasticity/uncertainty of driving forces (e.g., disturbances, populations dynamics)

RS7-b Probability of driving forces leading to a given outcome (or intermediate outcome)

RS7-c Variability (range of) of driving forces

RS7-d Time period that may be predicted

RS8 Storage characteristics

RS8-a Nutrient source-sink dynamics

RS8-b Spatial and temporal patterns in storage

RS9 Location

RS9-a Connectivity of resource system to nearby ecosystems of similar and different types

RS10 Ecosystem history ${ }^{\dagger}$

RS10-a Relevant geologic history

RS10-b Natural disaster history

RS10-c Human use and disturbance history 
Resource units (RU)

RU1 Resource unit mobility

RU1-a Mobile resource units $\$$

RU1-ai Outflows

RU1-aii Inflows

RU2-aiii Patch dynamics

RU2-b Stationary resource units $\$$

RU2 Growth or replacement rate

RU2-a Length of time to reproductive maturity

RU2-b Source-sink population dynamics (incl. migration patterns)

RU2-c Effective population size and reproductive rate

RU3 Interaction among resource units

RU3-a Competition within species (intraspecific competition)

RU3-b Competition between species (interspecific competition)

RU3-c Predation (incl. herbivory, parasitism)

RU3-d Mutualism

RU3-e Multilevel trophic interactions/cascades

RU4 Economic value

RU4-a Subsistence value

RU4-b Absolute economic value

RU4-c Relative economic value

RU5 Number of units

RU5-a Population (and subpopulation) dynamics

RU5-b Absolute size

RU5-c Relative size (of the population or of individuals in the population)

RU6 Distinctive markings

RU6-a Natural distinctive markings $\$$

RU6-b Artificial distinctive markings ${ }^{\S}$

RU7 Spatial and temporal distribution

RU7-a Spatial patchiness (heterogeneity of resource or habitat distribution over space)

RU7-b Temporal patchiness (heterogeneity of resource or habitat distribution over time, i.e., phenology)

${ }^{\dagger}$ A new attribute that we believe is a necessary addition to the

framework in order to understand the ecology of an SES.

Attributes where the frequency, magnitude/intensity, and extent of

activity or disturbance should be considered.

${ }^{\S}$ Modified from Ostrom (2007a).

'Modified from Ostrom (2007b).

Box 1. Justification for incorporation of select third-tier variables in the Resource System (RS) and Resource Unit (RU) subsystems.

\section{Resource system shape or configuration (RS3-b)}

Island biogeography and other theories from conservation biology also inform us that the shape of an ecosystem, particularly as measured by the ratio of edge to interior habitat, also affects the quality of the ecosystem (Harper et al. 2005). Edge and interior areas of terrestrial forest ecosystems have slightly different microclimates, including temperature, sunlight availability, wind speed and more, resulting in different species compositions on which human management or harvesting efforts may have varying impacts (Harper et al. 2005). Edge habitats are also more susceptible to invasion by non-native plant or animal species that can negatively impact native species populations (Brothers and Spingarn 1992) and decrease the value these native populations may have for users.

Contiguity of resource system to adjacent ecosystems of the same type (RS2-c)

Because user definitions of a resource system's boundaries (RS2$b$ ) may differ from the ecological boundaries of the ecosystem $(R S 2-a)$, the contiguity of a resource system within a larger ecosystem of the same type could have a profound impact on the ecology of a system. For instance, the location of a collectively owned patch of forest used for hunting wildlife within a larger national forest has implications for wildlife movement and population dynamics within the patch of forest. Island biogeography theory (MacArthur and Wilson 1967) tells us that a similar-sized patch of forest located within a matrix of farmland would have much smaller populations of wildlife within the patch available for hunting, and would not have the surrounding forest habitat as a source of wildlife.

\section{Stochasticityluncertainty of driving forces ( $R S 7-a)$}

The predictability of the ecological dynamics and interactions within a system are affected by many factors, one of the most important of which is the stochastic or uncertain nature of driving forces within the system. For instance, random (or apparently random) fluctuations in, say, fish population size or growth rate can dramatically impact the effectiveness of a fixed harvesting limit set by users on population viability and long-term sustainability. Additionally, uncertainty or stochasticity in the linkages between driving forces and resource system properties or outcomes can belie attempts by users to manage these properties.

\section{Temporal patchiness ( $R U$ T-b)}

Temporal patchiness in the distribution of a resource can affect resource use. For instance, available pasture may vary during the year as plant production and nutrient cycling rely on fluctuating rainfall patterns. For resource users relying on pastured livestock, seasonal rainfall variability can dictate the very well-being of households. In East Africa, precipitation levels are largely driven by the movement of the Intertropical Convergence Zone (ITCZ) causing long and short rainy seasons (Gatebe et al. 1999). Grazable lands increase during rainy periods, and contract in the dry season. The result is a bimodal pattern of yearly pasture availability that can be detrimental to resource users during dry periods.

Clearly, any single ecological attribute presented in Table 2 cannot be completely understood in isolation, and it is through the interaction of variables that we gain insights into the causal linkages within an SES. Indeed, the study of dynamic interactions constitutes the foundation of ecology, and the SES framework core subsystems (Table 1) emphasize the importance of interactions in social situations as well. Without the inclusion and consideration of the interaction between these attributes variables, the SES framework is, at best, incomplete in identifying the full set of variables that lead to SES outcomes, and at worst, may lead to policy prescriptions that fail to account for ecological processes that support or undermine the pursuit of sustainability.

\section{Ecological interactions}

The application to our YLW case of a modified SES framework that explicitly incorporates dynamic ecological processes enabled simultaneous recognition of the linked nature of social and ecological processes and disentanglement of the factors that influence harvesting decisions and species dynamics. Figure 2 tells the story of the YLW forest through a modified SES framework that recognizes social and ecological coproduction of outcomes. The figure incorporates sequential social action situations and 
Fig. 2. Application of a modified social-ecological system framework to Yellowwood Lake Watershed forest. Interactions and outcomes are part of an iterative process that feeds back into the Core Subsystems (RS, RU, GS, A) to shape both the social and biophysical environment.

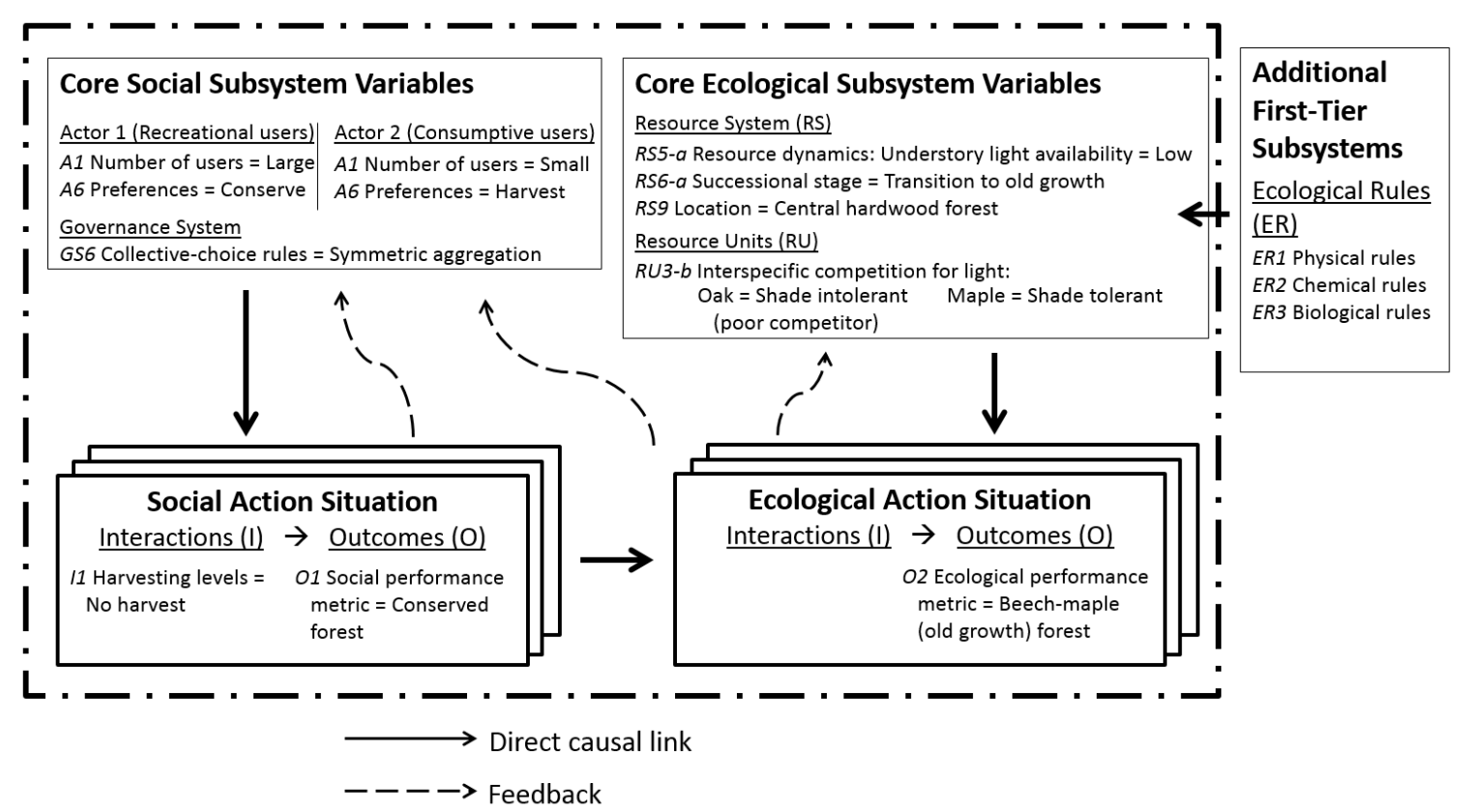

ecological interactions, and the attributes of the system that affect those processes. Whereas for many forest ecologists the causes of changes in the species composition of a forest are straightforward and tied to natural succession processes, the case demonstrates the potential usefulness of an approach that combines social and ecological processes in a single analytical framework and allows for the consideration of likely social-ecological outcomes as a result of alternative strategies and policies.

\section{CONCLUSIONS AND IMPLICATIONS}

Frameworks, theories, and models enable scholars to organize inquiry, explain phenomena, make predictions, and test hypotheses (Schlager 2007). The SES framework as initially constructed is limited in its ability to understand joint socialecological outcomes and human-environment problems because it excludes ecological models and theory from the study of social phenomena, or social production of outcomes.

We used the relatively simple case of human-aided forest succession in YLW forest as an example of a dynamic system that is difficult to understand in the absence of ecological theory or explicit incorporation of ecological variables in the SES framework. In YLW forest, the current transition from an oakto maple-dominated forest could be explained solely through the choice to conserve. However, if we step back in time and perform the same analysis, we would reach a point where the dominance of oak and other shade-intolerant species is also explained by the choice to conserve. The choice to conserve, i.e., to preserve the forest by excluding active management and timber harvesting, means that naturally occurring forest succession drives species composition dynamics, which change over time. Ecological variables and theories represent the missing link that can explain how the choice to conserve, i.e., not harvest, and suppress fires first produced a forest consisting of shade-intolerant species, followed by a gradual transition to a forest characterized by shadetolerant species. The story of YLW is one of social and ecological coproduction, and would be fundamentally incomplete in the absence of either. Fortunately, the SES framework is amenable to the inclusion of ecology, as demonstrated by this case. However, much work remains before it can provide an interdisciplinary foundation for the science of sustainability.

An adapted SES framework that meaningfully incorporates ecological thinking has several important implications for scholars and practitioners. These implications are constraining in that they add further complexity to already-complex systems, but also enabling in that they open the door to a broader set of potential levers for sustainability in systems that are inexorably linked. Resource managers like the foresters at YLW are confronted by a wide range of ecological systems and interested parties with divergent beliefs and preferences. The SES framework can aid these resource managers in describing alternative futures (Ostrom 2008) and unpacking presumed differences to illuminate potential underlying agreements.

Finally, the SES framework is a work in progress whose boldness is underscored more by the need for interdisciplinarity than the framework's current interdisciplinary diagnostic capacity. Our purpose is to provide a foundation for greater integration of ecology into the framework. We hope that other scholars with advanced ecological training will, through cooperation and contestation (Ostrom 1990), help to expand and use the SES framework so it can be claimed by multiple disciplines. Shared ownership may be costly, difficult, and at times contradictory; but if the architect of the framework showed us one thing, it is that the presumption of inevitable failure in these settings is far from assured (Ostrom 1990). 
Responses to this article can be read online at: http://www.ecologyandsociety.org/issues/responses. php/7239

\section{Acknowledgments:}

This article is a product of the Integrating Ecological Perspectives with the Social-Ecological System Framework Research Working Group at The Vincent and Elinor Ostrom Workshop in Political Theory and Policy Analysis at Indiana University, Bloomington, Indiana. An earlier version was presented at a Workshop Colloquium in October 2012, and we are indebted to the helpful feedback received by colleagues at the workshop. We are also indebted to unpublished work by Ursula Kreitmair and Michael Cox detailing variables within the social-ecological systems framework. We are grateful for the helpful comments of two anonymous reviewers. Last, but not least, we dedicate this paper to the memory of Elinor Ostrom, who provided unending encouragement that continues to resonate throughout our work.

\section{LITERATURE CITED}

Abrams, M. D. 2003. Where have all the white oak gone? BioScience 53(10):927-939. http://dx.doi.org/10.1641/0006-3568 (2003)053[0927:WHATWO]2.0.CO;2

Arnold, G., J. Bauer, B. Fischer, F. Fleischman, M. Midgley, S. K. Mincey, M. Paulson Priebe, K. Souza, C. Tucker, and S. Villamayor Tomas. 2008. An initial visit to the Yellowwood Lake Watershed forest. International Forestry Resources and Institutions Research Program working paper W07I-24. International Forestry Resources and Institutions Research Program, Workshop in Political Theory and Policy Analysis, Indiana University, Bloomington, Indiana, USA.

Benedick, R. E. 1998. Ozone diplomacy: new directions in safeguarding the planet. Harvard University Press, Cambridge, Massachusetts, USA.

Brothers, T. S., and A. Spingarn. 1992. Forest fragmentation and alien plant invasion of central Indiana old-growth forests. Conservation Biology 6(1):91-100. http://dx.doi.org/10.1046/ j.1523-1739.1992.610091.X

Chhatre, A., and A. Agrawal. 2008. Forest commons and local enforcement. Proceedings of the National Academy of Sciences of the United States of America 105(36):13286-13291. http://dx.doi. org/10.1073/pnas.0803399105

Chhatre, A., and A. Agrawal. 2009. Trade-offs and synergies between carbon storage and livelihood benefits from forest commons. Proceedings of the National Academy of Sciences of the United States of America 106(42):17667-17670. http://dx.doi. org/10.1073/pnas.0905308106

Coleman, E. A. 2009. Institutional factors affecting biophysical outcomes in forest management. Journal of Policy Analysis and Management 28(1):122-146. http://dx.doi.org/10.1002/pam.20405

Cox, M. 2011. Advancing the diagnostic analysis of environmental problems. International Journal of the Commons 5 (2):346-363.
Epstein, G., J. M. Vogt, S. K. Mincey, M. Cox, and B.C. Fischer. 2013. Missing ecology: integrating ecological perspectives with the social-ecological system framework. International Journal of the Commons 7(2):432-453.

Gatebe, C. K., P. D. Tyson, H. Annegarn, S. Piketh, and G. Helas. 1999. A seasonal air transport climatology for Kenya. Journal of Geophysical Research 104:14237-14244. http://dx.doi. org/10.1029/1998JD200103

Genkai-Kato, M., and S. R. Carpenter. 2005. Eutrophication due to phosphorus recycling in relation to lake morphometry, temperature, and macrophytes. Ecology 86(1):210-219. http://dx. doi.org/10.1890/03-0545

Gibson, C., J. T. Williams, and E. Ostrom. 2005. Local enforcement and better forests. World Development 33(2):273-284. http://dx.doi.org/10.1016/j.worlddev.2004.07.013

Gowdy, J., and L. Krall. 2013. The ultrasocial origin of the Anthropocene. Ecological Economics 95:137-147. http://dx.doi. org/10.1016/j.ecolecon.2013.08.006

Harper, K. A., S. E. MacDonald, P. J. Burton, J. Chen, K. D. Brosofske, S. C. Saunders, E. S. Euskirchen, D. Roberts, M. S. Jaiteh, and P.-A. Esseen. 2005. Edge influence on forest structure and composition in fragmented landscapes. Conservation Biology 19(3):768-782. http://dx.doi.org/10.1111/j.1523-1739.2005.00045. $\underline{\mathrm{x}}$

Holling, C. S. 2000. Theories for sustainable futures. Conservation Ecology 4(2): 7. [online] URL: http://www.consecol.org/vol4/iss2/ art7l

Homoya, M. A., D. B. Abrell, J. R. Aldrich, and T. W. Post. 1985. The natural regions of Indiana. Proceedings of the Indiana Academy of Science 94:245-84.

Husch, B., T. W. Beers, and J. A. Kershaw. 2003. Forest mensuration. John Wiley \& Sons, Hoboken, New Jersey, USA.

Indiana Department of Natural Resources, Division of Forestry (IDNR). 2008. Indiana state forests environmental assessment, 2008-2027: increased emphasis on management and sustainability of oak-hickory communities on the Indiana state forest system. IDNR, Indianapolis, Indiana, USA.

Janssen, M. A. 2010. Introducing ecological dynamics into common-pool resource experiments. Ecology and Society 15(2): 7. [online] URL: http://www.ecologyandsociety.org/vol15/iss $2 /$ art7/

MacArthur, R. H., and E. O. Wilson. 1967. The theory of island biogeography. Princeton University Press, Princeton, New Jersey, USA.

McGinnis, M. D., and E. Ostrom. 2014. Social-ecological system framework: initial changes and continuing challenges. Ecology and Society, 19(2): 30. http://dx.doi.org/10.5751/ES-06387-190230

Ostrom, E. 1990. Governing the commons. Cambridge University Press, Cambridge, UK. http://dx.doi.org/10.1017/CBO9780511807763

Ostrom, E. 2005. Understanding institutional diversity. Princeton University Press, Princeton, New Jersey, USA. 
Ostrom, E. 2007a. A diagnostic approach for going beyond panaceas. Proceedings of the National Academy of Sciences of the United States of America 104(39):15181-15187. http://dx.doi. org/10.1073/pnas.0702288104

Ostrom, E. 2007b. Sustainable social-ecological systems: an impossibility? Presented at the 2007 Annual Meeting of the American Association for the Advancement of Science, "Science and Technology for Sustainable Well-Being," 15-19 February, 2007, San Francisco, California. [online] URL: http://ssrn.com/ $\underline{\text { abstract }=997834}$

Ostrom, E. 2009. A general framework for analyzing sustainability of social-ecological systems. Science 325:419-422. http://dx.doi.org/10.1126/science.1172133

Ostrom, E., and M. Cox. 2010. Moving beyond panaceas: a multitiered diagnostic approach for social-ecological systems. Environmental Conservation 37(4):451-463. http://dx.doi.org/10.1017/ $\underline{\mathrm{S} 0376892910000834}$

Ostrom, V. 2008. The intellectual crisis in American public administration. Third edition. University of Alabama Press, Tuscaloosa, Alabama, USA.

Pagdee, A., Y. Kin, and P. J. Daugherty. 2006. What makes community forest management successful: a meta-study from community forests throughout the world. Society \& Natural Resources 19(1):33-52. http://dx.doi.org/10.1080/08941920500323260

Parson, E. A. 2003. Protecting the ozone layer: science and strategy. Oxford University Press, Oxford, UK. http://dx.doi. org/10.1093/0195155491.001.0001

Persha, L., A. Agrawal, and A. Chhatre. 2011. Social and ecological synergy: local rulemaking, forest livelihoods and biodiversity conservation. Science 331:1606-1608. http://dx.doi. org/10.1126/science. 1199343

Pierce, A. R., G. Parker, and K. Rabenold. 2006. Forest succession in an oak-hickory dominated stand during a 40-year period at the Ross Biological Reserve, Indiana. Natural Areas Journal 26:351-359. http://dx.doi.org/10.3375/0885-8608(2006)26[351:FSIAOD] 2.0. $\mathrm{CO} ; 2$

Poteete, A. R., M. A. Janssen, and E. Ostrom. 2010. Working together. Princeton University Press, Princeton, New Jersey, USA. http://dx.doi.org/10.1515/9781400835157

Redman, C. L., J. M. Morgan, and L. H. Kuby. 2004. Integrating social science into the long-term ecological research (LTER) network: social dimensions of ecological change and ecological dimensions of social change. Ecosystems 7(2):161-171. http://dx. doi.org/10.1007/s10021-003-0215-Z

Schlager, E. 2007. A comparison of frameworks, theories, and models of policy processes. Pages 293-319 in P. A. Sabatier, editor. Theories of the policy process. Second edition. Westview, Boulder, Colorado, USA.

Steffen, W., J. Grinevald, P. Crutzen, and J. McNeill. 2011. The Anthropocene: conceptual and historical perspectives. Philosophical Transactions of The Royal Society A: Physical, Mathematical and Engineering Sciences 369(1938):842-867. http://dx.doi.org/10.1098/ $\underline{\text { rsta.2010.0327 }}$
Yellowwood Lake Watershed Planning Group (YLWPG). 2006. The Yellowwood Lake Watershed Management Plan: protecting, enhancing, and conserving Yellowwood Lake and its watershed. Indiana Department of Natural Resources, Division of Forestry, Yellowwood State Forest, Nashville, Indiana, USA. [online] URL: http://www.in.gov/idem/nps/files/wmp_yellowwoodlake_4-46. pdf 